\title{
Response invalidity in empirical research: Causes, detection, and remedies.
}

DOI:

10.1016/j.jom.2018.12.002

\section{Document Version}

Accepted author manuscript

Link to publication record in Manchester Research Explorer

\section{Citation for published version (APA):}

Edwards, J. (2019). Response invalidity in empirical research: Causes, detection, and remedies. Journal of Operations Management, 65(1), 62-76. https://doi.org/10.1016/j.jom.2018.12.002

\section{Published in:}

Journal of Operations Management

\section{Citing this paper}

Please note that where the full-text provided on Manchester Research Explorer is the Author Accepted Manuscript or Proof version this may differ from the final Published version. If citing, it is advised that you check and use the publisher's definitive version.

\section{General rights}

Copyright and moral rights for the publications made accessible in the Research Explorer are retained by the authors and/or other copyright owners and it is a condition of accessing publications that users recognise and abide by the legal requirements associated with these rights.

\section{Takedown policy}

If you believe that this document breaches copyright please refer to the University of Manchester's Takedown Procedures [http://man.ac.uk/04Y6Bo] or contact uml.scholarlycommunications@manchester.ac.uk providing relevant details, so we can investigate your claim.

\section{OPEN ACCESS}


Response Invalidity in Empirical Research:

Causes, Detection, and Remedies

Jeffrey R. Edwards

Kenan-Flagler Business School

University of North Carolina at Chapel Hill

Campus Box 3490

Chapel Hill, NC, 27599-3490, USA

$+1-919-962-3144$

jredwards@unc.edu

In press, Journal of Operations Management. 


\begin{abstract}
Research in behavioral operations management and related areas relies heavily on selfreport measures. The utility of such measures depends on the extent to which the responses are valid, meaning they correspond to the thoughts and beliefs of respondents with regard to the phenomena under study. Response validity is undermined when respondents are unwilling or unable to provide adequate responses to survey questions, an issue that has generated an array of methods for screening and evaluating survey data and dealing with dubious responses. This article uses the work of Abbey and Meloy (2017) as a point of departure to examine the causes, detection, and remedies of response invalidity. The article concludes with recommendations for future research that treats response validity and its dimensions as methods factors that should be formally incorporated into statistical models.
\end{abstract}

Keywords: Survey research, self-report measures, response validation 
Response Invalidity 3

\section{Introduction}

Research in the social and behavioral sciences relies heavily on data collected using selfreport measures (DeVellis, 2017; Schwarz, 1999; Stone, Turkkan, Bachrach, Jobe, Kurtzman, \& Cain, 2000). Self-report measures are appropriate, if not essential, for studies that seek to understand the perceptions, beliefs, and attitudes of individuals. Self-report measures are also used when respondents describe the behavior of others, as when managers report the performance of their direct reports, or serve as key informants who describe situations, conditions, and events in organizational systems and settings. These and other uses of self-report measures are widespread in fields such as applied psychology and organizational behavior (Podsakoff \& Organ, 1986; Spector, 1994) and have become increasingly common in disciplines that include behavioral economics (Camerer, Loewenstein, \& Rabin, 2004), behavioral finance (Thaler, 2005), and operations management (Bendoly, van Wezel, \& Bacharach, 2015).

Concerns over the quality of data collected using self-report measures have generated an extensive methodological literature. Much of this literature addresses how to develop self-report measures that exhibit strong psychometric properties and construct validity, such that scores on these measures adequately reflect the underlying constructs of interest (DeVellis, 2017; Edwards, 2003; Nunnally \& Bernstein, 1994). A related issue is response validity, defined here as the extent to which data collected from a respondent reflect his or her actual thoughts and beliefs regarding the phenomena under study. In various guises, response validity has become a growing concern in empirical research (Huang, Liu, \& Bowling, 2015; Johnson, 2005; Meade \& Craig, 2012) and can be viewed as a complement to construct validity when evaluating the quality of self-report data.

The importance of response validity in operations management research is manifested by the recent article by Abbey and Meloy (2017), who focused on how data quality is affected by the attention respondents devote to the task of completing self-report measures. These authors provided a critical review of available techniques for assessing respondent attention, which they evaluated in terms of their objectivity and ease of implementation. The authors then applied 
three attention checks to data sets from 30 laboratory and survey studies. Their results yielded useful information concerning the prevalence of inattentive responding and shed some light on the effects of removing inattentive respondents on various statistical outcomes.

The present article builds on the work of Abbey and Meloy (2017) in several ways. First, this article goes beyond inattentive responding to address other factors that influence response validity, such as respondent personality, ability, and motivation, instrument design, and method of data collection. Second, it expands the procedures for evaluating response validity, drawing from the growing literature on this topic. Third, this article considers ways to handle low quality data other than dropping respondents, an approach that is widespread but costly in terms of sample size, statistical power, and loss of information.

\section{The meaning of response validity}

As noted earlier, response validity refers to the extent to which scores reflect the thoughts and beliefs of respondents concerning the phenomena of interest. Response validity is not the accuracy of scores in an objective sense, such as whether respondents rate their performance at levels that match ratings from their supervisors (Campbell \& Lee, 1988; Schoorman \& Mayer, 2008) or informants correctly describe the operational and financial performance of a firm (Ketokivi \& Schroeder, 2004). Rather, response validity involves the correspondence between the cognitions of a respondent (e.g., beliefs, perceptions, and evaluations of the self, others, and system-level attributes of firms) and the scores he or she reports as indicators of those cognitions. If the reported scores are aligned with the respondent's cognitions, then response validity is high, whereas if the scores are misaligned with what the respondent actually thinks, perceives, or feels, response validity would be low.

The concept of response validity has been discussed using various terms. For instance, Abbey and Meloy (2017) described a stereotyped response as one that does not accurately reflect the attitudes of the respondent. Other terms with similar meaning include protocol validity (Johnson, 2005; Kurtz \& Parrish, 2001), content nonresponsivity (Evans \& Dinning, 1983; Nichols, Greene, \& Schmolck, 1989), and low-quality data (DeSimone \& Harms, 2017). Some 
descriptions of response validity use terms that imply low motivation, characterizing respondents as careless (Curran, 2016; Greene, 1978; Meade \& Craig, 2012), inattentive (Maniaci \& Rogge, 2014), inconsistent (Nichols et al., 1989), random (Beach, 1989), or exerting insufficient effort (Dunn, Heggestad, Shanock, \& Theilgard, 2018; Huang et al., 2015). Other terms point to efforts by respondents to present themselves in certain ways, using tactics such as faking (Birkeland, Manson, Kisamore, Brannick, \& Smith, 2006; Ziegler, MacCann, \& Roberts, 2012) or impression management (McGrath, Mitchell, Kim, \& Hough, 2010; Paulhus, 1984). Unlike these terms, response validity refers to the correspondence between a respondent's actual and reported thoughts and beliefs, treating the causes of this correspondence as important but distinct from response validity itself.

The definition of response validity adopted here does not deny the importance of the accuracy of cognitions held by respondents. Indeed, much research that treats the organization as the unit of analysis relies on informants to describe characteristics of the organization, which requires that respondents who serve as informants have the knowledge and ability to report the information they are asked to provide. Informants are qualified to serve this purpose when they are exposed to the organizational situations, conditions, and events they describe, attend to and encode this information, and recall it in the form of cognitions they can reported at the time of measurement. Response validity picks up at this stage of the process, considering the extent to which cognitions held by respondents are adequately translated into scores that indicate what respondents actually think about the matters under investigation. Hence, the accuracy of informant reports requires not only that respondents have acquired the desired information, but also that they report this information in ways that are valid, such that the obtained data reflects what the respondents actually think.

The foregoing issues can be further clarified by considering the stages of the survey response process, as outlined in Table 1. The stages presented here were adapted from the seminal work by Tourangeau, Rips, and Rasinski (2000) on the psychology of survey responses (for alternative treatments, see Cannell, Miller, \& Oksenberg, 1981; Ericsson \& Simon, 1993; 
and Schwarz \& Sudman, 1996). As shown in Table 1, the response process is characterized in terms of five stages consisting of experience, comprehension, retrieval, judgment, and response. The accuracy of the cognitions held by respondents depends primarily on the experience stage, in which respondents are exposed to relevant situations, conditions, and events and attend to any aspects of the self that might be under study, form mental representations of this information, and encode and store the information in long-term memory. The translation of these cognitions into responses begins with the comprehension stage, where respondents attend to and interpret survey questions, attempt to understand what information is being requested, and link the survey questions to concepts as understood by the respondent. The third stage is retrieval, where respondents use cognitive strategies to retrieve specific information, draw from general memory structures, and fill in any missing details. At the judgment stage, respondents evaluate the information they have retrieved and integrate and edit the information to form a unified representation. Finally, at the response stage, the judged representation is mapped onto the response format of the question (e.g., rating scale, open-ended) which is then reviewed, edited, and submitted by the respondent. These last four stages of the survey response process are essential to response validity.

The stages outlined in Table 1 represent a logical progression that respondents would follow under idealized circumstances. In reality, some of the stages might be approximated or skipped entirely, and respondents could revert back to earlier stages or move through them in an order that differs from the sequence in Table 1. Nonetheless, these stages reinforce the idea that what might seem like a simple act of answering a survey question is actually a complex process with many interrelated components, and the manner in which this process unfolds can enhance or undermine the accuracy of the information available to the respondent and increase or decrease the validity of the emitted responses. These complexities apply regardless of whether respondents describe themselves and their personal situations or serve as informants of systemlevel attributes of organizations. In what follows, the survey response process in Table 1 serves as a backdrop as we examine the causes of response validity, how it can be assessed, and what 
can and should be done to address response validity in empirical research.

\section{Causes of response validity}

Response validity can be influenced by many factors. The following discussion organizes these factors into three categories that denote characteristics of the respondent, characteristics of the instrument, and the method of data collection.

\subsection{Characteristics of the respondent}

Studies of response validity have focused on factors that implicate characteristics of the respondent. The following discussion addresses three broad sets of characteristics that include respondent personality, ability, and motivation.

\subsubsection{Personality}

Several studies suggest that response validity is related to the personality of the respondent. Among the personality dimensions investigated, those that consistently relate to response validity include conscientiousness, agreeableness, and to a lesser extent, openness to experience (Bowling, Huang, Bragg, Khazon, Liu, \& Blackmore, 2016; Dunn et al., 2018; Maniaci \& Rogge, 2014; Ward, Meade, Allred, Pappalardo, \& Stoughton, 2017). These findings stand to reason given the nature of these personality dimensions (Digman, 1990; McCrae \& Costa, 2003). For instance, conscientiousness involves being attentive, dependable, and persistent, and agreeableness implies being cooperative and helpful. As such, when confronted with the task of completing a survey, respondents with these tendencies are likely to engage the task with care, effort, thoroughness, and the desire to provide useful information. In a somewhat different vein, openness to experience reflects intellectual curiosity, thoughtfulness, and inquisitiveness, and respondents with these qualities might view the survey experience as an opportunity to learn, explore, and express oneself.

\subsubsection{Ability}

Response validity also depends on the abilities of the respondent with respect to the task of completing the survey and the content of the survey itself. For instance, a respondent who has a limited vocabulary, poor verbal comprehension, or language skills that do not align with the 
survey will be unlikely to produce valid responses (Curran, 2016; Johnson, 2005). In addition, surveys place demands on respondents in terms of knowledge and recall of experiences and events, which can vary in their complexity, abstractness, and time since they transpired. Put simply, response validity requires that respondents have the abilities required to fulfill the communication and information demands of the survey (Bradburn, Sudman, \& Wansink, 2004).

\subsubsection{Motivation}

The effects of respondent motivation on response validity has been studied extensively. Much of this research is based on the assumption that, in general, respondents want to minimize the time and effort they devote to completing a survey (Dunn et al., 2018; Johnson, 2005). This assumption reflects the notion that, from the respondent's perspective, a survey is a chore that provides little intrinsic engagement or enjoyment. This assumption has been corroborated by research into the effort expended by respondents on surveys, as inferred from the time spent on the survey, the variability and pattern of responses, and the proportion of questions answered (Curran, 2016; DeSimone \& Harms, 2017; Huang et al., 2015; Maniaci \& Rogge, 2014; Meade \& Craig, 2012).

Whereas some respondents evidently view surveys as tasks to complete with minimal time and effort, others can experience surveys as intrinsically motivating, as when the topic of the survey appeals to the interests of the respondent (Maniaci \& Rogge, 2014; Meade \& Craig, 2012) or respondents enjoy the opportunity to examine and describe themselves (Johnson, 2005). Surveys can also be implemented in ways that foster extrinsic motivation, as when researchers offer incentives to participants who respond carefully (Bowling et al., 2016) or warn respondents they will not receive research participation credit unless they complete a survey with care and attention (Abbey \& Meloy, 2017; Dwight \& Donovan 2003; Huang, Curran, Keeney, Poposki, \& DeShon, 2012).

Other motivational factors that can distort survey responses involve the desire to present oneself in favorable ways. These factors include impression management, self-presentation bias, and faking good (Curran, 2016; Johnson, 2005; Meade \& Craig, 2012; Nichols et al., 1989; 
Paulhus, 1991). In some cases, respondents might misrepresent themselves or their situations in negative ways, such as exaggerating an illness in order to solicit medical attention (Curran, 2016) or complaining about purportedly unfair treatment to maintain self-esteem in the face of failure (Crocker \& Major, 1989; Ruggiero \& Marx, 1999). Unlike sources of response invalidity that signify lack of motivation, these factors involve concerted efforts to respond in ways that serve the goals of the respondent at the expense of the validity of the reported information.

\subsection{Characteristics of the instrument}

Response validity can also be impacted by characteristics of the instrument, including the construction and organization of the items, the instructions given to respondents, and the length of the survey.

\subsubsection{Item construction and organization}

The manner in which items are written, organized, and presented can greatly influence the obtained responses and their validity. Schwarz (1999) and Bradburn et al. (2004) review studies that identify various characteristics of items that influence how they are interpreted and answered, such as the simplicity and clarity of item wording, the construction of frequency and rating scales, open versus closed response formats, and the conversational norms that items invoke. Responses are also influenced by context effects, such as the order in which items are presented (Feldman \& Lynch, 1988; Harrison \& McLaughlin, 1993) and whether they are grouped with similar versus dissimilar items (McFarland, Ryan, \& Ellis, 2002; Schriesheim, Kopelman, \& Solomon, 1989).

\subsubsection{Instructions}

Instructions that accompany a survey can include appeals to complete the survey with care and attention. In some cases, these instructions refer to extrinsic incentives such as those described earlier, which make the receipt of outcomes valued by respondent contingent upon the effort invested in the survey (Abbey \& Meloy, 2017; Huang et al., 2012). In other cases, instructions can underscore the importance of respondent effort, attention to the study, and the overall quality of the obtained data (Meade \& Craig, 2012). 
Response Invalidity 10

\subsubsection{Length}

Response validity has also been linked to survey length. As respondents proceed through a long survey, they can lose interest or become fatigued, which can progressively undermine the validity of their answers to survey questions (Berry, Wetter, Baer, Larsen, Clark, \& Monroe, 1992; Meade \& Craig, 2012). Before starting a survey, respondents might also take stock of the task that lies before them and, if it appears long, effortful, and time-consuming, they could give superficial responses from the outset.

\subsection{Method of Data Collection}

Finally, response validity can also be affected by the method of data collection, such as whether a survey is administered online or using a paper-and-pencil format. Online surveys have generated concerns about response validity because they are often completed in uncontrolled conditions where respondents can be exposed to distractions and are isolated from cues that might foster engagement, such as a proctor who oversees the data collection process (Buchanan, 2000; Johnson, 2005; Meade \& Craig, 2012; Stanton \& Rogelberg, 2001). On the other hand, online surveys can influence the behavior of the respondent in real time using tactics that enhance response validity, such as preventing respondents from proceeding unless all the questions in a section have been answered. Available evidence suggests that, on balance, online and paper-and-pencil surveys elicit similar levels of respondent engagement and yield data of similar quality (Gosling, Vazire, Srivastava, \& John, 2004; Johnson, 2005). More research is needed to fully understand how response validity is affected by these and other methods of data collection, such as face-to-face interviews.

\subsection{Summary}

In combination, the foregoing aspects of the respondent, the instrument, and the method of data collection can markedly influence response validity. Research is needed to determine the separate and combined effects of these factors along with the magnitudes of these effects. This work would provide guidance for researchers to enhance the validity of responses when they are collected, as opposed to dealing with the consequences of response invalidity after the fact (cf. 
Aguinis \& Vandenberg, 2014).

\section{Detection}

Much of the research on response validity has focused on methods for assessing the degree to which responses can be considered valid (Abbey \& Meloy, 2017). These methods include the use of items intended to screen out invalid responses, the evaluation of responses in terms of their extremity, consistency, and pattern, and the length of time respondents spend on the survey. Details concerning these methods are discussed below.

\subsection{Screening items}

A common method for detecting response validity is to include screening items, which are intended to assess the attention, care, and effort of respondents while they complete a survey. Here, we consider three approaches for assessing response validity that use screening items. One approach relies on instructions to answer survey questions in particular ways. This approach can entail instructed response items, which ask participants to give a particular answer to a survey question. For instance, participants might be asked to select "strongly agree" on an agree versus disagree scale (Bowling et al., 2016) or choose "moderately accurate" on an accuracy scale (Curran, 2016; Huang et al., 2012). Similarly, instructional manipulation checks consist of statements that tell respondents how they should answer a set of questions. This technique was introduced by Oppenheimer, Meyvis, and Davidenko (2009), who presented an example in which respondents were given a question asking which of ten sports they played, prefaced by instructions to ignore the response options and instead click the heading of the page, which would advance to the next screen. In similar fashion, Hauser and Schwarz (2016) used the question, "Which of these personality traits best describe you and your personality? (click on all that apply)" followed by 12 personality trait options, along with instructions preceding the question which told respondents to ignore the personality items, select the option "other," and write "I read the instructions" in the accompanying text box. As noted by Maniaci and Rogge (2014), a key shortcoming of instructional manipulation checks is that they only detect whether respondents are attentive when reading instructions, as opposed to answering survey questions 
themselves.

A second technique that relies on screening items is the infrequency approach, which uses items for which virtually all valid responses should be the same. Such items can refer to activities that logically deviate from what respondents should experience, such as asking clerical workers how often they prepare agency budgets when doing so would be outside their job scope (Green \& Veres, 1990). Other items can describe situations or events that are vanishingly rare or even nonexistent, as when participants report whether they were born on February $30^{\text {th }}$ (Beach, 1989) or the extent to which they agree with items such as "I work twenty-eight hours in a typical work day" (Huang et al., 2015), "I have been to every country in the world" (Maniaci \& Rogge, 2014), or "I have exactly 354 best friends" (DeSimone \& Harms, 2017). Respondents who give inappropriate answers to screening items such as these are assumed to be disengaged from the survey task as a whole. Although this approach can be useful, screening items can come across as "trick" questions, which can annoy respondents and undermine the spirit of cooperation between the researcher and respondent that facilitates response validity (Costa \& McCrae, 2008).

A third approach is to use items that directly ask respondents the extent to which they completed the survey with care and attention (Abbey \& Meloy, 2017; Curran, 2016; DeSimone, Harms, \& DeSimone, 2015; Huang et al., 2015; Meade \& Craig, 2012). To illustrate, Huang et al. (2012) used a postsurvey self-report measure of effort that included items such as "I didn’t pay much attention to what the questions actually meant" and "I responded carelessly to the questions." Although this approach is clear and straightforward, it relies on the assumption that respondents will honestly and accurately report how they approached the task of completing the survey. Some respondents might hesitate to admit they did not take the survey seriously, and others could misunderstand how much effort and attention are, in fact, required to yield valid responses (Curran, 2016; DeSimone et al., 2015). Moreover, if respondents are disengaged to the extent that they provide invalid responses throughout a survey, they are similarly likely to give invalid responses to questions about how they approached the survey itself. In fact, as 
observed by Abbey and Meloy (2017), when such items include instructions to respond in a particular way (e.g., give a predetermined score on a rating scale), respondents often claim they paid attention and, at the same time, fail to respond according to the instructions.

\subsection{Outlier analysis}

Another method used to assess response validity is outlier analysis, which attempts to identify respondents whose scores are extreme relative to those of the full sample (Abbey \& Meloy, 2017; Bowling et al., 2016; Curran, 2016; DeSimone et al., 2015; Meade \& Craig, 2012). Outlier analyses can be conducted using univariate or multivariate techniques. With univariate outlier analysis, each survey item is considered individually, and cases with relatively extreme scores are identified (Meade \& Craig, 2012). Multivariate outlier analysis, on the other hand, identifies cases with extreme scores on multiple items considered jointly. Multivariate outliers are often screened using Mahalanobis' distance, which is a generalization of the Euclidean distance that takes into account the variances and covariances of the items involved (Cronbach $\&$ Gleser, 1953; Mahalanobis, 1936). Although outlier analysis can detect cases with relatively extreme scores, the responses of such cases are not necessarily invalid, because they could represent the actual standing of the cases on the dimensions being measured (Curran, 2016). Moreover, careless respondents could repeatedly choose options at any point on a rating scale, not necessarily at the extremes, and therefore would not be detected by outlier analysis (Meade \& Craig, 2012).

\subsection{Consistency analysis}

Another set of techniques for assessing response validity entails consistency analysis. These techniques rely on the assumption that participants who are attentive and motivated will provide patterns of responses that are internally consistent (Curran, 2016; Huang et al., 2012; Meade \& Craig, 2012). Consistency is manifested when respondents provide similar answers to items that reflect the same or similar constructs and give different answers to items that represent distinct constructs. The similarity of items used to gauge consistency is determined either by judging their content or by examining the interitem correlations using the obtained data. 
A straightforward approach to consistency analysis based on item content is odd-even analysis (Curran, 2016; Johnson, 2005; Meade \& Craig, 2012). With this approach, the items that constitute a scale are numbered sequentially and divided into sets with odd or even numbers, and the within-person correlation between the two sets is computed. Respondents whose withinperson correlations are considered sufficiently high are deemed attentive, whereas respondents with low correlations are regarded as inattentive, thereby calling into question the validity of their responses. The odd-even approach relies on the assumption that the items that constitute a measure are, in fact, similar in meaning, which bears the risk that low within-person correlations could reflect inconsistency of the items rather than the respondent. Moreover, respondents who are disengaged could give similar answers as they move through the items in a scale, which would yield consistent responses that nonetheless have questionable validity. Furthermore, as noted by Curran (2016), distinguishing odd and even items is but one of many ways items can be split into two sets, and different splits will generally yield different within-person correlations. This problem can be addressed by computing within-person correlations for all possible splits and averaging the resulting correlations for each respondent, yielding what Curran (2016) termed the Resampled Individual Reliability coefficient.

Another form of consistency analysis that relies on item content involves semantic synonyms and antonyms (Curran, 2016; DeSimone et al., 2015; Meade \& Craig, 2012). Semantic synonyms are items paired based on their linguistic similarity, such as "satisfied" and "happy." Unlike odd-even analysis, which pairs items from the same measure, semantic synonyms can be assembled from the same or different measures. Semantic antonyms, on the other hand, are items judged to be opposites based on their content, such as "happy" and "sad." Once semantic synonyms and antonyms are identified, within-person correlations between the resulting sets of items are computed, with the expectation that these correlations will be positive for semantic synonyms and negative for semantic antonyms among respondents who are attentive to the content of the items.

Consistency analysis can also be based on psychometric synonyms and antonyms, which 
are items deemed similar or dissimilar, respectively, based on their intercorrelations in the data at hand (Bowling et al., 2016; DeSimone et al., 2015; Dunn et al., 2018; Johnson, 2005; Meade \& Craig, 2012). Psychometric synonyms and antonyms can be identified in various ways, such as locating some predetermined number of item pairs with the highest and lowest correlations (e.g., 30 item pairs; Bowling et al., 2016; Huang et al., 2012; Meade \& Craig, 2012) or selecting item pairs with correlations that exceed some threshold, such as $+/-0.60$ (Curran, 2016; Meade \& Craig, 2012). Once the psychometric synonyms and antonyms have been chosen, within-person correlations are computed, and respondents whose correlations are deemed too small in absolute terms are regarded as inattentive, unmotivated, or disengaged, thereby calling into question the validity of their responses.

Regardless of how similar and dissimilar items are identified, consistency analysis usually relies on within-person correlations to assess the extent to which respondents give answers that are consistent. Unfortunately, this approach is problematic, because the correlation between two sets of scores does not capture whether the scores are similar in absolute terms, given that the scores within each set are centered at their respective means when the correlation is computed (Edwards, 1993). As a result, two sets of scores that differ by some constant can yield a high correlation, and this correlation will not change by increasing or decreasing the size of the constant. This problem is avoided when the similarity of the two sets of scores is quantified as the sum of absolute differences (Maniaci \& Rogge, 2014), although this approach suffers from the usual problems of using difference scores to assess the similarity between profiles (Cronbach, 1958; Edwards, 1993).

\subsection{Response patterns}

Response validity has also been assessed using long-string analysis, which involves counting the number of times a survey participant gives the same response to a series of items (Curran, 2016; Huang et al., 2012; Johnson, 2005; Meade \& Craig, 2012). This technique has been attributed to Costa and McCrae (2008), who used what they deemed a cooperative sample of 983 volunteers to conducted long-string analyses of the five response options for items on the 
NEO-PI-R. The maximum number of consecutive responses ranged from 6 for "strongly disagree" to 14 for "agree," and Costa and McCrae (2008) suggested that these counts could be used as criteria for identifying random responders. These criteria were used by Huang et al. (2012), whereas other criteria have been applied to different measures (Curran, 2016; Dunn et al., 2018; Johnson, 2005; Maniaci \& Rogge, 2014; Meade \& Craig, 2012). Given that multiple string lengths can be computed for each respondent using items throughout a survey, researchers have computed average string length as well as the maximum long string, which tend to yield similar results when applied as screening criteria (Meade \& Craig, 2012).

Although long-string analysis is relatively straightforward, the potential length of a string is capped by the number of items in a scale (Curran, 2016), such that different string lengths can be obtained for different scales even when a respondent is equally inattentive to each scale. Moreover, because long-string analysis is designed to assess responses that are the same for a set of items, it does not detect other patterns that could indicate response invalidity, such as alternating between two adjacent response options (Dunn et al., 2018; Johnson, 2005). To circumvent this problem, Dunn et al. (2018) recommended the Individual Response Variability Index, which is calculated as the within-person standard deviation of responses to a set of consecutive items. This index, as well as long-string analysis itself, is predicated on the assumption that the items being analyzed are indicators of different constructs and that the respondent actual standings on these constructs are at different levels (Curran, 2016; DeSimone et al., 2015; Dunn et al., 2018). If the items are homogeneous and written at the same level of intensity, then reporting the same score across the items would yield responses that should be considered valid. Moreover, some authors have characterized within-person variability not as evidence of response validity, but instead as an indicator of random responding (Marjanovic, Holden, Struthers, Cribbie, \& Greenglass, 2015). Ultimately, whether a particular pattern of responses should be deemed problematic depends on the pattern that would be expected if the respondent gave answers that were legitimate.

\subsection{Response time}


Response validity has also been evaluated using response time, which refers to how long a respondent spends on individual items, sets of items (e.g., a section or page), or the survey as a whole (Abbey \& Meloy, 2017; Curran, 2016; DeSimone et al., 2015; Dunn et al., 2018; Huang et al., 2012; Maniaci \& Rogge, 2014; Meade \& Craig, 2012). This approach is particularly feasible when surveys are administered online, because the associated software often provides tools that can record the time spent on the various elements of a survey (e.g., start time, end time, time spent on each page, time elapsed between answering consecutive questions). When response time is deemed too short, as when respondents spend less than two seconds per item (Huang et al., 2012), then the validity of such responses is called into question, assuming that some minimum amount of time is required to read and interpret an item and formulate and report a valid response. On the other hand, when response time is excessive, respondents might have disengaged from the survey, perhaps shifting their attention to competing tasks or tiring of the survey process (Abbey \& Meloy, 2017; Maniaci \& Rogge, 2014; Meade \& Craig, 2012). Determining how much response time is insufficient or excessive is complicated by various factors, such as variation in how fast respondents can read, the difficulty of the items, and the complexity of the response scale (e.g., choosing between two options versus calibrating a response on a multipoint rating scale). Thus, the utility of response time for assessing response validity might be limited to identifying respondents who have clearly devoted too little time to do justice to the survey (Curran, 2016; Dunn et al., 2018), acknowledging that this designation depends on the design and content of the survey itself and the abilities of the respondent as they apply to the survey task.

\subsection{Responses to open-ended questions}

For surveys that present open-ended questions, some researchers have suggested that the content and length of the obtained responses can be used as evidence of respondent engagement and, hence, response validity (Abbey \& Meloy, 2017; Huang et al., 2015). As noted by Abbey and Meloy (2017), open-ended questions and the responses they generate are very adaptable and can provide a wealth of diagnostic information, such as evidence of demand effects, how 
respondents interpreted various questions, sections, and instructions within the survey, and the attitudes, moods, and feelings experienced by the respondents while completing the survey. Naturally, open-ended responses are subject to different interpretations among researchers, so this information should be treated as qualitative data to be evaluated and coded by multiple judges, and their degree of agreement should be evaluated (Gwet, 2012; LeBreton \& Senter, 2008; Shoukri, 2010).

\subsection{Missing responses}

Finally, perhaps the most obvious form of response invalidity occurs when respondents simply do not answer survey questions (DeSimone et al., 2015; Johnson, 2005). If the number of missing responses is considered small, then missing data techniques can be used to retain respondents whose protocols are incomplete (Allison, 2002; Enders, 2010; Graham, 2012; Maniaci \& Rogge, 2014). However, if the amount of missing responses is deemed excessive, then the validity of the entire protocol might be called into question. An important caveat noted by DeSimone et al. (2015) is that missing data can affect the application of other methods for assessing response validity. For instance, skipped items consume little or no time, which implies that response times should be adjusted for the number of items a respondent actually completes. Moreover, missing data undermine the application of techniques that use responses to items, such as outlier analysis, consistency analysis, and response patterns (e.g., missing data interferes with counts used for long-string analysis). As such, it might be sensible to impute missing data before these screening techniques are applied (DeSimone et al., 2015), bearing in mind that doing so does not alleviate the response validity problems that missing data suggest.

\subsection{Summary}

As the preceding review indicates, researchers face a wide array of methods for evaluating response validity. In general, there is little basis for preferring one method over another, because the methods are designed to assess different aspects of response validity. For instance, long-string analysis examines whether respondents give the same answer to a set of items, outlier analysis detects extreme answers to individual items, and response time assesses 
whether respondents moved too quickly through a survey, regardless of the answers they give. Not surprisingly, correlations among scores yielded by the various detection methods tend to be modest, with the exception of methods designed to assess similar response patterns, such as oddeven analysis and psychometric synonyms (Huang et al., 2012). As such, researchers should choose those detection methods that are best suited to the forms of response validity they want to assess. If researchers prefer a broad assessment of response validity, then multiple detection methods can be employed (Curran, 2016).

In addition to choosing methods for assessing response validity, researchers must decide how to use the information generated by these methods. Perhaps the most common approach is to develop cutoff criteria to designate responses as valid versus invalid. In some cases, there is clear justification for treating responses as invalid, as when participants give answers that are logically impossible (e.g., being born on February 30). In other cases, researchers have relied on judgment calls. For instance, Costa and McCrae (2008) established cutoffs for long-string analysis based on the maximum number of identical answers given by respondents who were considered "normal" and "cooperative" (p. 187) Similarly, Huang et al. (2012) used what they termed an "educated guess" (p. 114) to adopt two seconds per item as a minimum for adequate response time. Although the authors who proposed these cutoffs acknowledged them as matters of opinion, they have been adopted elsewhere as general standards (Bowling et al., 2016; DeSimone \& Harms, 2017; Huang et al., 2012; Johnson, 2005). In some instances, researchers use scores generated by detection methods to identify respondents who are extreme relative to the sample. For instance, Johnson (2005) created histograms of individual reliability coefficients and designated respondents at the low ends of the distributions as invalid. Likewise, Meade and Craig (2012) recommended the odd-even consistency index, the long-string index, and Mahalanobis' D for assessing response validity but noted that using these indices requires "inspection of their frequency distributions in order to identify a suitable cutoff value" (p. 16). When cutoff criteria are applied on several detection methods used together, the proportion of respondents classified as invalid can increase dramatically, particularly when the 
methods assess distinct aspects of response validity. For instance, Abbey and Meloy (2017) applied three methods that included logical statements, directed queries, and manipulation checks to 30 data sets. When applied separately, the percentages of respondents identified as inattentive ranged from approximately $14 \%$ to $20 \%$, but when all three methods were combined, the percentage rose to nearly 36\%. Likewise, DeSimone and Harms (2017) applied eight detection methods to an online sample of respondents and found that the percentage identified as providing low-quality data ranged from $5 \%$ to $40 \%$ for the individual methods but increased to $76 \%$ when the eight methods were combined. Naturally, these percentages depend on the stringency of the cutoff criteria used, and in principle, the information generated by detection methods could be left in continuous form, which would avoid the difficulties associated with establishing cutoffs in the first place. These issues come into focus when researchers use detection methods to implement remedies to response invalidity, a topic to which we now turn.

\section{Remedies}

When response invalidity is detected, researchers can choose from among various remedies. These remedies vary widely in terms of their prevalence, ease of implementation, and impact on sample size. Three general categories of remedies are considered here.

\subsection{Removing Respondents}

Perhaps the most widespread approach to handling response invalidity is to remove the offending respondents (Abbey \& Meloy, 2017; Bowling et al., 2016; DeSimone et al., 2015; Huang et al., 2015; Johnson, 2005; Meade \& Craig, 2012). With this approach, researchers confront the aforementioned challenges of deciding how many criteria to apply and establishing cutoff criteria to determine which respondents to discard. Removing respondents who violate cutoff criteria might seem prudent and conservative, because the questionable responses are purged entirely from the data. However, this approach comes with the cost of decreased sample size and the associated reduction in statistical power. These drawbacks can be particularly severe when several detection methods are used concurrently, which can drastically reduce sample size. 
A somewhat less extreme version of this approach is to apply screening criteria to each section of a survey and remove responses from the sections separately, as opposed to dropping respondents entirely when they give invalid responses to any part of a survey. This version is based on the premise that response validity is likely to vary during the course of completing a survey (Huang et al., 2015; Maniaci \& Rogge, 2014; Meade \& Craig, 2012), and identifying responses as invalid for certain parts of a survey should not be taken as evidence that the entire survey protocol is invalid. Taken to its logical extreme, this approach would require assessing the validity of each response to each survey item and treating invalid responses as missing data. Of course, this approach is feasible only for detection methods that involve individual responses, such as response time and outlier analysis, as opposed to methods that involve multiple items (e.g., consistency analysis, response patterns) or use screening items that are not themselves of substantive interest.

When invalid responses are identified individually, researchers should consider using techniques for handling missing data. This recommendation is based on the premise that invalid responses are akin to missing data because, even though the responses are present, they have no more utility than if they were absent (Curran, 2016). Methods for dealing with missing data have generated a substantial literature (Allison, 2002; Enders, 2010; Graham, 2012; Little \& Rubin, 2002), the bulk of which indicates that commonly used techniques, such as listwise deletion, pairwise deletion, and mean substitution, should be abandoned in favor of multiple imputation, the expectation maximization algorithm, and full-information maximum likelihood estimation. The viability of these and other missing data methods depends on the mechanisms by which data are missing, which in the present context refers to the reasons why responses are invalid. If the probability that a response is invalid does not depend on the variable being measured, either in isolation or after controlling for other variables, then the aforementioned methods for handling missing data can be applied. However, if the probability of a missing response depends on the variable being measured, as when responses to a conscientiousness scale are more likely to be invalid for respondents who are low on conscientiousness, then procedures for handling missing 
data are more complicated. These and other details regarding the use of missing data techniques are discussed in the methodological literature on missing data, including the sources cited here.

\subsection{Conducting Subgroup Analyses}

Rather than removing respondents designated as invalid, researchers can treat them as a subgroup of the full sample and conduct analyses to determine whether and how the distinction between valid and invalid responses influences the obtained results. Whereas removing respondents treats invalid responses as inherently problematic, subgroup analysis focuses on the effects of response invalidity on the findings and conclusions drawn from a study, treating these effects as empirical matters to be examined on a study-by-study basis.

Subgroup analyses can take two basic forms. The first involves creating two or more nonoverlapping subgroups representing different levels of response validity, conducting analyses in parallel fashion within each subgroup, and comparing results across the subgroups (Costa \& McCrae, 1997; Johnson, 2005; Kurtz \& Parrish, 2001; Maniaci \& Rogge, 2014). For instance, Johnson (2005) created subgroups of respondents who scored in the lowest and highest quartiles on response consistency indices based on odd-even analysis and psychometric antonyms. Within each subgroup, Johnson (2005) conducted principal components analysis of items designed to assess the five-factor model of personality (Goldberg, 1999). A similar approach was taken by Kurtz and Parrish (2001), who used an index of semantic similarity to create three subgroups who exhibited low, moderate, and high levels of response inconsistency and, across the three subgroups, compared reliabilities and convergent and discriminant validities of measures of the five-factor model (Costa \& McCrae, 1997; Goldberg, 1992). In some studies, results for subgroups are compared statistically, as when differences in internal consistency reliability coefficients are tested using the chi-square statistic (Maniaci \& Rogge, 2014). Statistical tests such as these provide more definitive information about the differences between subgroups than examining whether results for the subgroups support the same hypothesis or seem to exhibit the same general pattern.

A second form of subgroup analysis involves part-whole comparisons in which results 
from the full sample are compared to those obtained from subsamples that exclude cases identified as providing invalid responses (Abbey \& Meloy, 2017; Curran, 2016; DeSimone et al., 2015; Huang et al., 2012). This approach might be attractive when the number of invalid respondents is deemed too small to analyze as a separate subgroup. However, the full sample and any subsample both include all cases considered valid, and because of this overlap, results for the full sample and its subsamples are likely to be similar, particularly when the proportion of valid respondents is large. Moreover, because the full sample and any given subsample are not independent, conventional statistical tests for comparing the obtained parameter estimates cannot be applied. Another concern is that any subsample is necessarily smaller than the full sample from which it is obtained, which means that statistical comparisons between the subsample and full sample are confounded with differences in sample size. This concern applies to the results of Abbey and Meloy (2017), who reported difference in chi-square statistics for factor models estimated using full samples and their corresponding subsamples from which respondents who failed attention checks were removed. The chi-square statistics were generally smaller for the subsamples than the full samples, but these comparisons are undermined by the fact that the chisquare is a function of sample size, given that it is computed as $N-1$ times the minimum value of the fit function (Jöreskog \& Sörbom, 1988). As such, reducing sample sizes by dropping respondents will reduce the chi-square statistic even if the fit function remains constant. This dependence of the chi-square statistic on sample size is one of the primary reasons that fit indices that are independent of sample size have been developed (Gerbing \& Anderson, 1992). On balance, if the subgroup approach is used, it is advisable to create separate subgroups rather than relying on part-whole comparisons, provided the subgroups are sufficiently large to allow meaningful statistical comparisons.

\subsection{Using Response Validity as a Moderator Variable}

A natural extension of subgroup analysis is to treat response validity as a moderator variable (Curran, 2016; Kurtz \& Parrish, 2001; McGrath et al., 2010; Oppenheimer et al., 2009; Piedmont, McCrae, Riemann, \& Angleitner, 2000). Like subgroup analysis, this approach is 
intended to determine whether response validity influences the relationships between substantive variables. However, whereas the subgroup approach focuses on results within separate subgroups, the moderator approach leaves the full sample intact and examines whether relationships vary across levels of one or more variables that serve as indicators of response validity. Moderator variables used to represent response validity can be categorical, as when respondents are classified into groups intended to represent different degrees of validity (Oppenheimer et al., 2009). This approach is analogous to the subgroup approach when effects obtained in different subgroups are compared statistically (Maniaci \& Rogge, 2014). Moderator variables can also be continuous, thereby treating response validity as a matter of degree (Kurtz \& Parrish, 2001; Piedmont et al., 2000). Categorical moderator variables should be used only when the corresponding indicators of response validity are themselves categorical, as when a respondent did or did not answer a screening question correctly. When indicators of response validity are continuous, as is usually the case, they should be analyzed in that form, thereby avoiding the usual problems with categorizing continuous variables (Cohen, 1983; MacCallum, Zhang, Preacher, \& Rucker, 2002). Moreover, by treating response validity indices as continuous variables, researchers can circumvent the dilemma of choosing cutoffs to designate responses as valid versus invalid. Whether treated as categorical or continuous variables, the moderator approach consists of forming product terms between substantive predictor variables and the moderator variables that serve as indicators of response validity and testing the increment in variance explained by these product terms, after controlling for the substantive and moderator variables (Aiken \& West, 1991; Cohen, 1978).

To illustrate the use of response validity as a moderator variable, assume that $X$ and $Y$ are substantive variables of interest and $Z$ is an indicator of response validity. The moderating effect of $Z$ on the relationship between $X$ and $Y$ can be analyzed with the following regression equation:

$$
Y=b_{0}+b_{1} X+b_{2} Z+b_{3} X Z+e .
$$

The moderating effect of $Z$ can be tested by determining whether $b_{3}$ differs from zero or, equivalently, by assessing the increment in the variance of $Y$ explained by $X Z$ after $X$ and $Z$ are 
controlled. The effect of $\mathrm{Z}$ on the relationship between $\mathrm{X}$ and $\mathrm{Y}$ can be clarified by rewriting Eq. 1 in terms of simple slopes (Aiken \& West, 1991):

$$
Y=\left(b_{0}+b_{2} Z\right)+\left(b_{1}+b_{3} Z\right) X+e .
$$

With the coefficient estimates from Eq. 1 in hand, Eq. 2 can be used to observe the effects of $Z$ on the relationship between $X$ and $Y$ by substituting selected values of $Z$ (e.g., string lengths, degrees of within-person consistency, various amounts of time spent on the survey).

Eq. 1 can be expanded to include several indices of response validity simultaneously. For instance, to examine the effects of three indices labeled $Z_{1}, Z_{2}$, and $Z_{3}$, Eq. 1 would become:

$$
Y=b_{0}+b_{1} X+b_{2} Z_{1}+b_{3} Z_{2}+b_{4} Z_{3}+b_{5} X Z_{1}+b_{6} X Z_{2}+b_{7} X Z_{3}+e .
$$

The moderating effects of all three response validity indices can be assessed with a joint test of $b_{5}, b_{6}$, and $b_{7}$, which is equivalent to testing the increment in variance explained by $X Z_{1}, X Z_{2}$, and $X Z_{3}$ after taking into account $X, Z_{1}, Z_{2}$, and $Z_{3}$. As before, the effects of $Z_{1}, Z_{2}$, and $Z_{3}$ on the relationship between $X$ and $Y$ can be examined by rewriting Eq. 3 in terms of simple slopes:

$$
Y=\left(b_{0}+b_{2} Z_{1}+b_{3} Z_{2}+b_{4} Z_{3}\right)+\left(b_{1}+b_{5} Z_{1}+b_{6} Z_{2}+b_{7} Z_{3}\right) X+e .
$$

Another modification of Eq. 1 can be used when the effects of response validity are believed to be particularly pronounced at extreme values of a response validity index. In such cases, the index and its square can be used as moderator variables, as follows:

$$
Y=b_{0}+b_{1} X+b_{2} Z+b_{3} Z^{2}+b_{4} X Z+b_{5} X Z^{2}+e .
$$

The moderating effect of $Z$ is assessed by a joint test of $b_{4}$ and $b_{5}$. Rewriting Eq. 5 in terms of simple slopes yields:

$$
Y=\left(b_{0}+b_{2} Z+b_{3} Z^{2}\right)+\left(b_{1}+b_{4} Z+b_{5} Z^{2}\right) X+e .
$$

Using the coefficient estimates from Eq. 5, Eq. 6 can be used to examine how the relationship between $X$ and $Y$ varies across levels of $Z$. Note that the simple slope in Eq. 6 differs from that in Eq. 2 by the inclusion of $Z^{2}$, which serves to determine whether the moderating effect of $Z$ on the relationship between $X$ and $Y$ depends on the level of $Z$ itself. These examples illustrate some of the many ways that the moderating effects of response validity can be examined. Further details can be found in the methodological literature on moderated regression (Aiken \& West, 1991) and 
its extensions to moderated structural equation modeling (Schumacker \& Marcoulides, 1998).

\section{Summary and Conclusion}

The work of Abbey and Meloy (2017) is an important contribution to the understanding of response validity in behavioral operations management research. The present article builds on this work by considering the causes of response validity, expanding the methods that can be used to assess response validity, and considering remedies to response invalidity other than removing respondents. Looking ahead, there are several promising lines of work that should be pursued. First, the causes of response validity discussed earlier can be translated into interventions that reduce the incidence and degree of invalid responding. For example, respondent ability can be addressed by providing definitions of terms used in a survey and ensuring that respondents have exposure to the situations and experiences that the survey is designed to assess. Intrinsic motivation to engage in a survey can be enhanced by linking the topic and questions of the survey to the interests and goals of the respondent, and extrinsic motivation can be strengthened by providing incentives for completing the survey with care, attention, and effort (Abbey \& Meloy, 2017; Dwight \& Donovan 2003; Huang et al.,2012). Response validity can also be influenced by attending to recommendations for survey design, making sure the survey is well organized, items are clear and concise, and response scales are readily interpreted and easy to apply (Bradburn et al., 2004; DeVellis, 2017; Schwarz, 1999). Finally, response validity can be improved by implementing surveys in ways that engage the respondent in the data collection process, as when the researcher is present with respondents while the survey is completed or delivers questions to the respondent in an interview format.

Second, methods for assessing response validity should be supplemented by techniques for tracking the thinking and behavior of respondents in real time while they complete a survey. For instance, some researchers attribute inadequate responding to insufficient effort of the respondent (DeSimone et al., 2015; Dunn et al., 2018; Huang et al., 2012; Huang et al., 2015). Screening methods currently in use do not directly assess respondent effort, but instead provide trace evidence that insufficient effort might be the reason for inadequate responding. Methods 
for measuring cognitive effort are available that involve cardiovascular activity, respiration rate, pupillary response, and blood glucose levels (De Rivecourt, Kuperus, Post, \& Mulder, 2008; Fairclough \& Houson, 2004; Peysakhovich, Causse, Scannella, \& Dehais, 2015; Piquado, Isaacowitz, \& Wingfield, 2010). Because these methods are unobtrusive, they do not rely on whether respondents are willing and able to describe the effort they expended while completing a survey (Abbey \& Meloy, 2017; Curran, 2016; DeSimone et al., 2015; Huang et al., 2015; Meade \& Craig, 2012). Similarly, to verify whether response invalidity is due to lack of attention (Abbey \& Meloy, 2017; Morgeson, Spitzmuller, Garza, \& Campion, 2016), eye-tracking procedures (Duchowski, 2007; Galesic, Tourangeau, Couper, \& Conrad, 2008) could be used to assess the frequency and duration of respondent attention to items and responses options, an approach that is feasible when surveys are completed using computer-based technologies. These suggestions are based on the premise that the reasons for inadequate responding correspond to latent variables that are not directly observed by the researcher, and like any latent variables, multiple indicators that rely on different methods are needed to tap into the processes involved.

Third, despite the volume of research on methods for detecting response invalidity, there is relatively little evidence that documents the extent to which response validity affects empirical results and substantive conclusions. Available evidence reported in the various articles reviewed here suggests that the effects of response invalidity are generally modest. To shed further light on this issue, research is needed that includes response validity and its dimensions as variables in models that estimate the relationships among substantive variables. With this approach, the extent to which response validity affects parameter estimates and substantive conclusions can be rigorously evaluated. This perspective is consistent with the broader literature on the use of methods factors in structural equation models (Eid, Nussbeck, Geiser, Cole, Gollwitzer, \& Lischetzke, 2008; Kenny \& Kashy, 1992; Marsh, 1989; Marsh \& Grayson, 1995; Widaman, 1985; Williams \& McGonagle, 2016; Wothke, 1995). Like any method factor, response validity should be measured and incorporated into statistical models to advance our understanding of its meaning and effects. 
In sum, the growing body of research on response validity, of which Abbey and Meloy (2017) is an exemplar, has the potential to improve substantive research in behavioral operations management and related fields. There have been great strides in methods for assessing response validity, which can be embellished with methods that rely on different measurement approaches. Likewise, there are numerous opportunities for investigating the causes of response validity and its effects on the findings of empirical research. Ultimately, these effects should be assessed on a study-by-study basis, given that response validity is likely to vary across samples, measures, and settings. This approach will help researchers accumulate evidence on the nature, causes, and consequences of response validity, which will help strengthen the substantial body of empirical research that relies on self-report measures. 


\section{References}

Abbey, J. D., \& Meloy, M. G. 2017. Attention by design: Detecting inattentive respondents to improve data quality. Journal of Operations Management, 53-56, 63-70.

Aguinis, H., \& Vandenberg, R. J. 2014. An ounce of prevention is worth a pound of cure: Improving research quality before data collection. Annual Review of Organizational Psychology and Organizational Behavior, 1, 569-595.

Aiken, L. A., \& West, S. G. 1991. Multiple regression: Testing and interpreting interactions. Newbury Park, CA: Sage.

Allison, P. D. 2002. Missing data. Thousand Oaks, CA, Sage.

Beach, D. A. 1989. Identifying the random responder. The Journal of Psychology, 123, 101103.

Bendoly, E., van Wezel, W., \& Bacharach, D. G. (Eds.). 2015. Handbook of behavioral operations management. Oxford: Oxford University Press.

Berry, D. T. R., Wetter, M. W., Baer, R. A., Larsen, L., Clark, C., \& Monroe, K. 1992. MMPI-2 random responding indices: Validation using a self-report methodology. Psychological Assessment, 4, 340-345.

Birkeland, S. A., Manson, T. M., Kisamore, J. L., Brannick, M. T., \& Smith, M. A. 2006. A meta-analytic investigation of job applicant faking on personality measures. International Journal of Selection and Assessment, 14, 317-329.

Bowling, N. A., Huang, J. L., Bragg, C. B., Khazon, S., Liu, M., \& Blackmore, C. E. 2016. Who cares and who is careless? Insufficient effort responding as a reflection of respondent personality. Journal of Personality and Social Psychology, 111, 218-229.

Bradburn, N., Sudman, S., \& Wansink, B. 2004. Asking questions (2 ${ }^{\text {nd }}$ ed).). San Francisco: Jossey Bass.

Buchanan, T. 2000. Potential of the Internet for personality research. In M. H. Birnbaum (Ed.), Psychological experiments on the Internet (pp. 121-140. San Diego, CA: Academic Press. 
Camerer, C. F., Loewenstein, G., \& Rabin, M. (Eds). 2004. Advances in behavioral economics. New York: Russell Sage Foundation.

Campbell, D. J., \& Lee, C. 1988. Self-appraisal in performance evaluation: Development versus evaluation. Academy of Management Review, 13, 302-314.

Cannell, C. F., Miller, P. V., \& Oskenberg, L. 1981. Research on interviewing techniques. Sociological Methodology, 12, 389-437.

Cohen, J. 1978. Partialed products are interactions: Partialed powers are curve components. Psychological Bulletin, 85, 858-866.

Cohen, J. 1983. The cost of dichotomization. Applied Psychological Measurement, 7, 249-253.

Costa, P. T., Jr., \& McCrae, R. R. 1997. Stability and change in personality assessment: The Revised NEO Personality Inventory in the Year 2000. Journal of Personality Assessment, 68, 86-94.

Costa, P. T., Jr., \& McCrae, R. R. 2008. The Revised NEO Personality Inventory (NEO-PI-R. In D. H. Saklofske (Ed.), The SAGE handbook of personality theory and assessment (Vol. 2: Personality measurement and testing) (pp. 179-198. Thousand Oaks, CA: Sage.

Crocker, J., \& Major, B. 1989. Social stigma and self-esteem: The self-protective properties of stigma. Psychological Review, 96, 608-630.

Cronbach, L. J. 1958. Proposals leading to analytic treatment of social perception scores. In R. Tagiuri \& L. Petrullo (Eds.), Person perception and interpersonal behavior (pp. 353-379. Stanford, CA: Stanford University Press.

Cronbach, L. J., \& Gleser, G. C. 1953. Assessing the similarity between profiles. Psychological Bulletin, 50, 456-473.

Curran, P. G. 2016. Methods for the detection of carelessly invalid responses in survey data. Journal of Experimental Social Psychology, 66, 4-19.

De Rivecourt, M., Kuperus, M. N., Post, W. J., \& Mulder, L. J. M.). 2008. Cardiovascular and eye activity measures as indices for momentary changes in mental effort during simulated flight. Ergonomics, 51, 1295-1319. 
DeSimone, J. A., \& Harms, P. D. 2017. Dirty data: The effects of screening respondents who provide low-quality data in survey research. Journal of Business and Psychology, DOI 10.1007/s10869-017-9514-9.

DeSimone, J. A., Harms, P. D., \& DeSimone, A. J. 2015. Best practice recommendations for data screening. Journal of Organizational Behavior, 36, 171-181.

DeVellis, R. F. 2017. Scale development: Theories and applications (4th ed.). Newbury Park, CA: Sage.

Digman, J. M. 1990. Personality structure: Emergence of the five-factor model. Annual Review of Psychology, 41, 417-440.

Duchowski, A. 2017. Eye tracking methodology: Theory and practice (3 ${ }^{\text {rd }}$ ed.). Cham, Switzerland: Springer International.

Dunn, A. M., Heggestad, E. D., Shanock, L. R., \& Theilgard, N. 2018. Intra-individual response variability as an indicator of insufficient effort responding: Comparison to other indicators and relationships with individual differences. Journal of Business and Psychology, 33, 105-121.

Dwight, S. A., \& Donovan, J. J. 2003. Do warnings not to fake reduce faking? Human Performance, 16, 1-23.

Edwards, J. R. 1993. Problems with the use of profile similarity indices in the study of congruence in organizational research. Personnel Psychology, 46, 641-665.

Edwards, J. R. 2003. Construct validation in organizational behavior research. In J. Greenberg (Eds.), Organizational behavior: The state of the science $2^{\text {nd }}$ ed., pp. 327-371. Mahwah, NJ: Erlbaum.

Eid, M., Nussbeck, F. W., Geiser, C., Cole, D. A., Gollwitzer, M., \& Lischetzke, T. 2008. Structural equation modeling of multitrait-multimethod data: Different models for different types of methods. Psychological Methods, 13, 230-253.

Enders, C. K. 2010. Applied missing data analysis. New York: The Guilford Press.

Ericsson, K. A., \& Simon, H. A. 1993. Protocol analysis: Verbal reports as data. Cambridge, 


\section{MA: MIT Press.}

Evans, R. G., \& Dinning, W. D. 1983. Response consistency among high F scale scorers on the MMPI. Journal of Clinical Psychology, 39, 246-248.

Fairclough, S. H., \& Houston, K. 2004. A metabolic measure of mental effort. Biological Psychology, 66, 177-190.

Feldman, J. M., \& Lynch, J. G., Jr. 1988. Self-generated validity and other effects of measurement of belief, attitude, intention, and behavior. Journal of Applied Psychology, $73,421-435$.

Galesic, M., Tourangeau, R., Couper, M. P., \& Conrad, F. G. 2008. Eye-tracking data: New insights on response order effects and other cognitive shortcuts in survey responding. Public Opinion Quarterly, 72, 892-913.

Gerbing, D. W., \& Anderson, J. C. 1992. Monte Carlo evaluations of goodness of fit indices for structural equation models. Sociological Methods \& Research, 21, 132-160.

Goldberg, L. R. 1992. The development of markers for the Big-Five factor structure. Psychological Assessment, 4, 26-42.

Goldberg, L. R. 1999. A broad-bandwidth, public domain, personality inventory measuring the lower-level facets of several five-factor models. In I. Mervielde, I. Deary, F. De Fruyt, \& F. Ostendorf (Eds.), Personality psychology in Europe (Vol. 7, pp. 7-28. Tilburg, The Netherlands: Tilburg University Press.

Gosling, S. D., Vazire, S., Srivastava, S., \& John, O. P. 2004. Should we trust web-based studies? A comparative analysis of six preconceptions about internet questionnaires. American Psychologist, 59, 93-104.

Graham, J. W. 2012. Missing data: Analysis and design. New York: Springer.

Green, S. B., \& Veres, J. G. 1990. Evaluation of an index to detect inaccurate respondents to a task analysis inventory. Journal of Business and Psychology, 5, 47-61.

Greene, R. L. 1978. An empirically derived MMPI carelessness scale. Journal of Clinical Psychology, 34, 407-410. 
Gwet, K. L. 2012. Handbook of inter-rater reliability: The definitive guide to measuring the extent of agreement among multiple raters (3rd ed.). Gaithersburg, MD: Advanced Analytics.

Harrison, D. A., \& McLaughlin, M. E. 1993. Cognitive processes in self-report responses: Tests of item context effects in work attitude measures. Journal of Applied Psychology, 78, 129-140.

Hauser, D. J., \& Schwarz, N. 2016. Attentive turkers: MTurk participants perform better on online attention checks than do subject pool participants. Behavior Research Methods, $48,400-407$.

Huang, J. L., Curran, P. G., Keeney, J., Poposki, E. M., \& DeShon, R. P. 2012. Detecting and deterring insufficient effort respond to surveys. Journal of Business and Psychology, 27, 99-114.

Huang, J. L., Liu, M. \& Bowling, N. 2015. Insufficient effort responding: Examining an insidious confound in survey data. Journal of Applied Psychology, 100, 828-845.

Johnson, J. A. 2005. Ascertaining the validity of individual protocols from web-based personality inventories. Journal of Research in Personality, 39, 103-129.

Jöreskog, K. G., \& Sörbom, D. 1988. LISREL VII. Chicago: SPSS, Inc.

Kenny, D. A., \& Kashy, D. A. 1992. Analysis of the multitrait-multimethod matrix by confirmatory factor analysis. Psychological Bulletin, 112, 165-172.

Ketokivi, M. A., \& Schroeder, R. G. 2004. Perceptual measures of performance: Fact or fiction? Journal of Operations Management, 22, 247-264.

Kurtz, J. E., \& Parrish, C. L. 2001. Semantic response consistency and protocol validity in structured personality assessment: The case of the NEO-PI-R. Journal of Personality Assessment, 76, 315-332.

LeBreton, J. M., \& Senter, J. L. 2008. Answers to 20 questions about interrater reliability and interrater agreement. Organizational Research Methods, 11, 815-852.

Little, R. J. A., \& Rubin, D. B. 2002. Statistical analysis with missing data 2nd ed. New York: 
Wiley.

MacCallum, R., Zhang, S., Preacher, K. J., \& Rucker, D. D. 2002. On the practice of dichotomization of quantitative variables. Psychological Methods, 7, 19-40.

Mahalanobis, P. C. 1936. On the generalized distance in statistics. Proceedings of the National Institute of Sciences of India, 2, 49-55.

Maniaci, M. R., \& Rogge, R. D. 2014. Caring about carelessness: Participant inattention and its effects on research. Journal of Research in Personality, 48, 61-83.

Marjanovic, Z., Holden, R., Struthers, W., Cribbie, R., \& Greenglass, E. 2015. The inter-item standard deviation (ISD): An index that discriminates between conscientious and random responders. Personality and Individual Differences, 84, 79-83.

Marsh, H. W. 1989. Confirmatory factor analyses of multitrait-multimethod data: Many problems and a few solutions. Applied Psychological Measurement, 13, 335-361.

Marsh, H. W., \& Grayson, D. 1995. Latent variable models of multitrait-multimethod data. In R. H. Hoyle (Ed.), Structural equation modeling: Concepts, issues, and applications (pp. 177-198. Thousand Oaks, CA: Sage.

McCrae, R. R., \& Costa, P. T., Jr. 2003. Personality in adulthood: A five-factor theory perspective 2nd ed.). New York: The Guilford Press.

McFarland, L. A., Ryan, A. M., \& Ellis, A. 2002. Item placement on a personality measure: Effects on faking behavior and test measurement properties. Journal of Personality Assessment, 78, 348-369.

McGrath, R. E., Mitchell, M., Kim, B. H., \& Hough, L. 2010. Evidence for response bias as a source of error variance in applied assessment. Psychological Bulletin, 136, 450-470.

Meade, A. W., \& Craig, S. B. 2012. Identifying careless responses in survey data. Psychological Methods, 17, 437-455.

Morgeson, F. P., Spitzmuller, M., Garza, A. S., \& Campion, M. A. 2016. Pay attention! The liabilities of respondent experience and carelessness when making job analysis judgments. Journal of Management, 42, 1904-1933. 
Nichols, D. S., Greene, R. L., \& Schmolck, P. 1989. Criteria for assessing inconsistent patterns of item endorsement on the MMPI: Rationale, development, and empirical trials. Journal of Clinical Psychology, 45, $239-250$.

Nunnally, J. C., Bernstein, I. H. 1994. Psychometric theory (3rd ed.). New York: McGraw-Hill Book Company.

Oppenheimer, D. M., Meyvis, T., \& Davidenko, N. 2009. Instructional manipulation checks: Detecting satisficing to increase statistical power. Journal of Experimental Social Psychology, 45, 867-872.

Paulhus, D. L. 1984. Two-component models of socially desirable responding. Journal of Personality and Social Psychology, 46, 598-609.

Paulhus, D. L. 1991. Measurement and control of response bias. In J. P. Robinson, P. R. Shaver, \& L. S. Wrightsman (Eds.), Measures of personality and social psychological attitudes (pp. 17-59. New York: Academic Press.

Peysakhovich, V., Causse, M., Scannella, S., \& Dehais, F. 2015. Frequency analysis of a taskevoked pupillary response: Luminance-independent measure of mental effort. International Journal of Psychophysiology, 97, 30-37.

Piedmont, R. L., McCrae, R. R., Riemann, R., \& Angleitner, A. 2000. On the invalidity of validity scales: Evidence from self-reports and observer ratings in volunteer samples. Journal of Personality and Social Psychology, 78, 582-593.

Piquado, T., Isaacowitz, D., \& Wingfield, A 2010. Pupillometry as a measure of cognitive effort in younger and older adults. Psychophysiology, 47, 560-569.

Podsakoff, P. M., \& Organ, D. W. 1986. Self-reports in organizational research: Problems and prospects. Journal of Management, 12, 531-544.

Ruggiero, K. M., \& Marx, D. M. 1999. Less pain and more to gain: Why high status group members blame their failure on discrimination. Journal of Personality and Social Psychology, 77, 774-784.

Schoorman, F. D., \& Mayer, R. C. 2008. The value of common perspectives in self-reported 
appraisals: You get what you ask for. Organizational Research Methods, 11, 148-159.

Schriesheim, C. A., Kopelman, R. E., \& Solomon, E. 1989. The effect of grouped versus randomized questionnaire format on scale reliability and validity: A three-study investigation. Educational and Psychological Measurement, 49, 487-508.

Schoorman, F. D., \& Mayer, R. C. 2008. The value of common perspectives in self-reported appraisals: You get what you ask for. Organizational Research Methods, 11, 148-159.

Schwarz, N. \& Sudman, S. (Eds.). 1996. Answering questions: Methodology for determining cognitive and communicative processes in survey research. San Francisco: Jossye-Bass.

Schumacker, R. E., \& Marcoulides, G. A. (Eds.). 1998. Interaction and nonlinear effects in structural equation modeling. Mahwah, NJ: Erlbaum.

Schwarz, N. 1999. Self-reports: How the questions shape the answers. American Psychologist, $54,93-105$.

Shoukri, M. M. 2010. Measures of interobserver agreement and reliability 2 nd edition. Boca Raton, FL: Chapman \& Hall.

Spector, P. E. 1994. Using self-report questionnaires in OB research: A comment on the use of a controversial method. Journal of Organizational Behavior, 15, 385-392.

Stanton, J. M., \& Rogelberg, S. G. 2001. Using internet/intranet web pages to collect organizational research data. Organizational Research Methods, 4, 200-217.

Stone, A. A., Turkkan, J. S., Bachrach, C. A., Jobe, J. B., Kurtzman, H. S., \& Cain, V. S. (Eds.). 2000. The science of self-report: Implications for research and practice. Mahwah, NJ: Erlbaum.

Thaler, R. H. (Ed.). 2005. Advances in behavioral finance (Vol. II, Roundtable Series in Behavioral Economics. Princeton: Princeton University Press.

Tourangeau, R., Rips, L. J., \& Rasinski, K. 2000. The psychology of survey response. New York: Cambridge University Press.

Ward, M. K., Meade, A. W., Allred, C. M., Pappalardo, G., \& Stoughton, J. W. 2017. Careless response and attrition as sources of bias in online survey assessments of personality traits 
and performance. Computers in Human Behavior, 76, 417-430.

Widaman, K. F. 1985. Hierarchically nested covariance structure models for multitraitmultimethod data. Applied Psychological Measurement, 9, 1-26.

Williams, L. J., \& McGonagle, A. K. 2016. Four research designs and a comprehensive analysis strategy for investigating common method variance with self-report measures using latent variables. Journal of Business and Psychology, 31, 339-359.

Wothke, W. 1995. Covariance components analysis of the multitrait-multimethod matrix. In P. E. Shrout \& S. T. Fiske (Eds.), Personality research, methods, and theory: A festschrift honoring Donald W. Fiske (pp. 125-144. Hillsdale, NJ: Erlbaum.

Ziegler, M., MacCann, C., \& Roberts, R. D. (Eds.). 2012. New perspectives on faking in personality assessment. New York: Oxford University Press. 


\section{Table 1}

Stages of the response process

Stage Specific processes

Experience Exposure to relevant situations, conditions, and events

Attention to aspects of the self

Formulation of mental representations

Encoding and storing information

Comprehension Attention to questions and instructions

Interpret the meaning of the questions

Understand what information is requested

Link question content to relevant concepts

Retrieval Generate retrieval strategy

Retrieve specific information

Draw from general memories

Construct missing details

Judgment Assess completeness and relevance of information retrieved

Integrate information into a unified representation

Edit representation as deemed appropriate

Response Map judgment onto response format

Review and edit response

Submit response

Adapted from Tourangeau, Rips, and Rasinski (2000, Table 1.1, p. 8). 